\title{
Geniposide Alleviates
}

\section{Amyloid-Induced Synaptic Injury by Protecting Axonal Mitochondrial Trafficking}

\author{
Haijing Zhang ${ }^{1,2,3 \dagger}$, Chunhui Zhao ${ }^{1,3,4 \dagger}$, Cui Lv ${ }^{1,3,5}$, Xiaoli Liu' ${ }^{6,7}$, Shijing Du ${ }^{1,3,6}, \mathrm{Zhi}^{\mathrm{Li}}{ }^{1,3,6}$, \\ Yongyan Wang 1,3,4,6 and Wensheng Zhang 1,3,6,7*
}

${ }^{1}$ Beijing Area Major Laboratory of Protection and Utilization of Traditional Chinese Medicine, Beijing Normal University, Beijing, China, ${ }^{2}$ College of Life Science, Beijing Normal University, Beijing, China, ${ }^{3}$ Engineering Research Center of Natural Medicine, Ministry of Education, Beijing Normal University, Beijing, China, ${ }^{4}$ Institute of Chinese Materia Medica, China Academy of Chinese Medical Sciences, Beijing, China, ${ }^{5}$ Laboratory of Immunology for Environment and Health, Shandong Analysis and Test Center, Shandong Academy of Science, Jinan, China, ${ }^{6}$ College of Resources Science Technology, Beijing Normal University, Beijing, China, ${ }^{7}$ Engineering Research Center of Sanqi Biotechnology and Pharmaceutical, Kunming, China

OPEN ACCESS

Edited by:

Hansen Wang

University of Toronto, Canada

Reviewed by:

Stefano L. Sensi,

University of California, Irvine, USA

P. Hemachandra Reddy

Texas Tech University Health Sciences

Center, USA

Oliver Wirths,

University of Göttingen, Germany

*Correspondence:

Wensheng Zhang

zws@bnu.edu.cn

${ }^{\dagger}$ These authors have contributed equally to this work.

Received: 13 November 2016 Accepted: 26 December 2016

Published: 25 January 2017

Citation:

Zhang H, Zhao C, Lv C, Liu X, Du S,

Li Z, Wang Y and Zhang W (2017)

Geniposide Alleviates

Amyloid-Induced Synaptic Injury by

Protecting Axonal Mitochondrial

Trafficking.

Front. Cell. Neurosci. 10:309. doi: 10.3389/fncel.2016.00309
Synaptic and mitochondrial pathologies are early events in the progression of Alzheimer's disease (AD). Normal axonal mitochondrial function and transport play crucial roles in maintaining synaptic function by producing high levels of adenosine triphosphate and buffering calcium. However, there can be abnormal axonal mitochondrial trafficking, distribution, and fragmentation, which are strongly correlated with amyloid- $\beta(A \beta)$-induced synaptic loss and dysfunction. The present study examined the neuroprotective effect of geniposide, a compound extracted from gardenia fruit in $A \beta$-treated neurons and an $A D$ mouse model. Geniposide alleviated $A \beta$-induced axonal mitochondrial abnormalities by increasing axonal mitochondrial density and length and improving mitochondrial motility and trafficking in cultured hippocampal neurons, consequently ameliorating synaptic damage by reversing synaptic loss, addressing spine density and morphology abnormalities, and ameliorating the decreases in synapse-related proteins in neurons and APPswe/PS1dE9 mice. These findings provide new insights into the effects of geniposide administration on neuronal and synaptic functions under conditions of $A \beta$ enrichment.

Keywords: axonal transport, mitochondrial trafficking, amyloid $\beta$, geniposide, synaptic loss, spine morphology

\section{INTRODUCTION}

Mitochondrial damage and synaptic dysfunction are early events in the pathogenesis of Alzheimer's disease (AD; Reddy and Beal, 2008; Hauptmann et al., 2009; Reddy, 2009; Reddy et al., 2012). Synapses, which are the basic structural foundations of signal transduction in the central nervous system, form connections, and transmit chemical signals among neurons (Billups and Forsythe, 2002; Li et al., 2004). Severe structural and functional damage to synapses fundamentally cause cognitive and memory dysfunctions (Du et al., 2008; Adalbert and Coleman, 2013). Changes in the density and morphology of synapses and dendritic spines can be detected in the cerebral cortex and hippocampus of AD patients (DeKosky et al., 1996). Cognitive dysfunction is more strongly correlated with synaptic loss than with senile plaques, neurofibrillary tangles, neural loss, or gliosis (Pozueta et al., 2013). 
Synapses require a large amount of energy provided by mitochondria, which involves mitochondrial fusion, fission, and transport from the soma. Mitochondria are distributed throughout neurons, including at synapses, via transfer through axons and dendrites. The proper intracellular distribution of the mitochondria is critical for the normal physiological functions of neuronal cells (Cai and Tammineni, 2016), such as neurotransmission, synaptic plasticity, and axonal outgrowth (Li et al., 2004). Abnormal distribution and transport disorders of the mitochondria can be observed in $\mathrm{AD}$ models (Stokin et al., 2005; Du et al., 2010; Sheng and Cai, 2012; Umeda et al., 2015) and influence the synthesis of neurotransmitters, the release of synaptic vesicles, and calcium homeostasis, ultimately resulting in synaptic dysfunction and adenosine triphosphate (ATP) deficiency (Billups and Forsythe, 2002; Hollenbeck, 2005; Verstreken et al., 2005). In this process, amyloid- $\beta(A \beta)$ is regarded as the major toxic molecule (Rui et al., 2006; Du et al., 2010).

$\mathrm{A} \beta$ is transported to the mitochondria via receptor for advanced glycation end products (RAGE; Takuma et al., 2009), the translocase of the outer membrane (TOM) machinery (Hansson Petersen et al., 2008; Reddy, 2009), or endoplasmic reticulum-mitochondrial crosstalk (Hedskog et al., 2013). A $\beta$ progressively accumulates in the neuronal mitochondria of $\mathrm{AD}$ mouse models overexpressing $\mathrm{A} \beta, \mathrm{AD}$ brains, and cultured neurons (Manczak et al., 2006, 2011; Reddy and Beal, 2008; Reddy, 2009; Calkins et al., 2011). The accumulation of $A \beta$ in the mitochondria occurs before the deposition of extracellular $\mathrm{A} \beta$ plaques and increases with age, particularly in synaptic mitochondria, which are vulnerable to cumulative damage, and induces the exaggeration of synaptic and mitochondrial injuries, such as the overproduction of reactive oxygen species (ROS; Manczak et al., 2006), decreased ATP, and hypometabolism (Cardoso et al., 2004; Du and Yan, 2010). Recent studies have shown that neuronal axonal mitochondria exhibited significantly repressed mobility and increased fragmentation (Du et al., 2010; Calkins and Reddy, 2011). Increasing evidence suggests that $\mathrm{A} \beta$-induced synaptic mitochondrial dysfunction contributes to synaptic injury (Du et al., 2008, 2010; Calkins et al., 2011; Calkins and Reddy, 2011; Fang et al., 2015). Thus, strategies to protect synaptic mitochondria against the structural and functional damage of $\mathrm{A} \beta$ may effectively prevent the deterioration of synaptic mitochondrial dysfunction and halt $\mathrm{AD}$ progression.

Geniposide (Zhao et al., 2016a), an iridoid glucoside compound isolated from gardenia fruit (Gardenia jasminoides Ellis, Rubiaceae), attenuated the oligomeric $\mathrm{A} \beta_{1-42}$-induced mitochondrial dysfunction by restoring ATP generation, mitochondrial membrane potential, and cytochrome c oxidase and caspase-3/-9 activity by reducing ROS production and cytochrome c leakage, as well as by inhibiting apoptosis (Lv et al., 2014a, 2015). Most studies also focused on the neuroprotective effect of geniposide against brain diseases, especially neurodegenerative disorders (Gao et al., 2014; Liu et al., 2015; Zhang et al., 2015). However, the protective effect of geniposide on axonal mitochondrial trafficking and synaptic injury in neurons remains unclear. The outcome of this study on cultured neurons showed that geniposide treatment significantly alleviates $\mathrm{A} \beta$-induced synaptic structural and morphological injuries by protecting axonal mitochondrial trafficking and morphology.

\section{MATERIALS AND METHODS Chemicals}

Geniposide (Zhao et al., 2016b; purity > 98\%) was purchased from the National Institute for the Control of Pharmaceutical and Biological Products (Beijing, China) and was free of endotoxins. 1,1,1,3,3,3-Hexafluoro-2-propanal (HFIP) and penicillin/streptomycin were obtained from Sigma (St. Louis, MO, USA). Fetal bovine serum (FBS), B27, and Neurobasal-A medium were purchased from Gibco (Waltham, MA, USA).

\section{Mice and Drug Administration}

Experimental mPrP-APPswe/PS1dE9 (APP/PS1) doubly transgenic mice and $\mathrm{C} 57 \mathrm{BL} / 6$ mice were purchased from Beijing HFK Bio-Technology Co., Ltd. Nine-month-old male mice were individually housed under a $12 \mathrm{~h}$ light/dark cycle at an ambient temperature of $23 \pm 1^{\circ} \mathrm{C}$ and relative humidity of $55 \pm 5 \%$ and were given food and water ad libitum. Before the experiment, the mice were housed under these conditions for 2-3 days to allow them to adapt to the environment. APP/PS1 mice were randomly categorized into the treatment groups or the vehicle group and treated with either geniposide $(12.5,25$, or $50 \mathrm{mg} / \mathrm{kg} /$ days; $n=$ $15)$ or water $(n=15)$, respectively, for 3 months via intragastric administration. Age-matched C57BL/6 mice were fed water as the vehicle control $(n=15)$. Geniposide was dissolved in water within $24 \mathrm{~h}$ before use. Equal volumes of liquid were given to each group daily for 3 months before the mice were sacrificed.

All animal procedures performed in this study were approved by the Beijing Normal University Laboratory Animal Care and Use Committee in accordance with the National Institute of Health "Guidelines for the Care and Use of Laboratory Animals" (NIH Publications No. 8023, revised 1996). The mice were sacrificed by cervical dislocation after being anesthetized. All efforts were made to minimize the number of animals used and their suffering.

\section{Oligomeric $A \beta_{1-42}$ Preparation}

Oligomeric $A \beta_{1-42}$ was prepared from commercially available synthetic peptides (Sigma Chemical Co., St. Louis, MO, USA), as previously described (Dahlgren et al., 2002; Yin et al., 2011). The lyophilized peptide was resuspended in cold HFIP at a concentration of $1 \mathrm{mg} / \mathrm{mL}$ and aliquoted into microcentrifuge tubes to quickly obtain $0.1 \mathrm{mg}$ stocks. The stocks were stored at room temperature and protected from light for 2-4 h before the removal of HFIP under gentle vacuum, thereby leaving a thin transparent film of peptides on the internal surface of the tube. The stocks were stored at $-20^{\circ} \mathrm{C}$. For the aggregation protocols, HFIP-treated peptides were dissolved in anhydrous dimethyl sulfoxide at $5 \mathrm{mM}$ and diluted to $100 \mu \mathrm{M}$ in Ham's F12 Nutrient Mixture (Thermo Fisher Scientific, Waltham, MA, USA). The diluted peptides were incubated at $4^{\circ} \mathrm{C}$ for $24 \mathrm{~h}$ to obtain oligomeric $\mathrm{A} \beta_{1-42}$. 


\section{Hippocampal Neuronal Culture and Treatment}

One-day-old male C57BL/6 mice were purchased from Beijing Vital River Laboratory Animal Technology Co., Ltd., and transported within a specific pathogen-free, air permeable, and bacteria shield shipping box. The mice were sacrificed by cervical dislocation.

Primary hippocampal neurons were prepared from the hippocampi of 1 day-old (newborn) pups. The hippocampi were dissected in cold D-Hanks solution. Tissues were collected and washed in D-Hanks, and $0.05 \%(\mathrm{v} / \mathrm{v})$ trypsin was added for digestion at $37^{\circ} \mathrm{C}$ for $20 \mathrm{~min}$. Digestion was terminated by adding FBS to a final concentration of $10 \%(\mathrm{v} / \mathrm{v})$. Cells were collected by centrifugation at $800 \times \mathrm{g}$ for $10 \mathrm{~min}$ to remove the D-Hanks solution and were then resuspended in Neurobasal-A medium (Thermo Fisher Scientific, Waltham, MA, USA) supplemented with 2\% (v/v) B27 (Thermo Fisher Scientific).

For the various analyses, cells were plated onto 6-, 12-, and 96-well-plates or glass-bottom dishes with four chambers (CELLview, Greiner, Germany) $\left(\sim 5 \times 10^{4}\right.$ cells $\left./ \mathrm{mL}\right)$ pre-coated with poly-D-lysine $(10 \mu \mathrm{g} / \mathrm{mL})$. The cells were cultured at $37^{\circ} \mathrm{C}$ and $5 \% \mathrm{CO}_{2}$ until use. The initial medium was removed after $4 \mathrm{~h}$ and replaced with fresh medium. After 14 days, the medium was replaced with Neurobasal-A medium without serum and phenol red (which affect the aggregation of $A \beta$ ). The primary cultured hippocampal neurons were pre-incubated for $24 \mathrm{~h}$ in the absence or presence of geniposide $(2.5,5$, or 10 $\mu \mathrm{M})$ before adding oligomeric $A \beta_{1-42}(200 \mathrm{nM})$ for $24 \mathrm{~h}$ to assess the protective effect of geniposide on the $A \beta_{1-42}$-treated neurons.

\section{Western Blot Assay}

The brain tissue or neuron samples were lysed in 10 volumes $(\mathrm{w} / \mathrm{v})$ of radio-immunoprecipitation assay buffer containing a cocktail of complete protease and phosphatase inhibitors and were centrifuged at $15,000 \times \mathrm{g}$ for $10 \mathrm{~min}$ at $4^{\circ} \mathrm{C}$. The protein concentration of the supernatant was determined using the BCA method. Proteins were examined by Western blot analysis using standard protocols. Equal amounts of proteins were loaded and resolved by $10 \%$ sodium dodecyl sulfate polyacrylamide gel electrophoresis and transferred to nitrocellulose membranes (Millipore, Billerica, MA, USA). The membranes were incubated in blocking solution (5\% skim milk in PBST, $20 \mathrm{mM}$ Tris$\mathrm{HCl}, 150 \mathrm{mM} \mathrm{NaCl}, 0.1 \%$ Tween-20) at room temperature for $1.5 \mathrm{~h}$. The membranes were incubated and gently shaken overnight (at $4^{\circ} \mathrm{C}$ ) in PBST containing 5\% skim milk and the indicated primary antibodies from among the following: monoclonal rabbit antibodies against c-AMP response element binding protein (CREB, 1:400, Cell Signaling, Beverley, MA, USA), and GAPDH (1:3000, Cell Signaling); polyclonal rabbit antibodies against phosphorylated $\mathrm{Ca}^{2+} /$ calmodulin dependent protein kinase II $\alpha$ (p-CaMKII $\alpha, 1: 8000$, Santa Cruz, CA, USA); and monoclonal mouse antibodies against synaptophysin (1:500, Abcam, Cambridge, UK), CaMKII $\alpha$ (1:250, Santa Cruz), phosphorylated CREB (p-CREB, 1:400, Cell Signaling), postsynaptic density protein-95 (PSD-95, 1:500, Abcam), and $\beta$ actin (1:2000, Santa Cruz). After four washes with PBST, the membranes were incubated for $1.5 \mathrm{~h}$ at room temperature with the corresponding secondary antibodies. The membranes were washed four times with PBST and detected with an infrared imaging system (Odyssey). The intensity of the blots was analyzed and compared using NIH Image program.

\section{ROS Measurement}

ROS were measured with $2^{\prime}, 7^{\prime}$-dichlorodihydrofluorescein diacetate (DCFH-DA). The cell-permeable DCFH-DA can be oxidized to dichlorofluorescein (DCF) by ROS in the cytoplasm and emit intensely fluorescence. After incubation with $A \beta_{1-42}$ in the presence and absence of geniposide for $24 \mathrm{~h}$, cultured neurons were washed with PBS and incubated with $10 \mu \mathrm{M}$ DCFH-DA for $30 \mathrm{~min}$ at $37^{\circ} \mathrm{C}$ in an incubator with $5 \% \mathrm{CO}_{2}$. Fluorescence images were captured using a laser-scanning confocal microscope (TCS-SPE, Leica, Germany). Fluorescence intensity was analyzed using NIH ImageJ program.

\section{Axonal Mitochondrial Density Assay and Length Measurement}

Hippocampal neurons at 14 day in vitro (DIV) were used for axonal mitochondrial density assay, and the length of these neurons was measured after the treatments. Neurons cultured in glass-bottom dishes with four chambers (CELLview, Greiner, Germany) were incubated with MitoTracker Red (Thermo Fisher Scientific, Waltham, MA, USA) at $100 \mathrm{nM}$ for $20 \mathrm{~min}$ at $37^{\circ} \mathrm{C}$ and $5 \% \mathrm{CO}_{2}$. Neurons were fixed in $4 \%$ paraformaldehyde for 20 min after being permeabilized with $0.5 \%$ Triton X-100 in $0.1 \%$ sodium citrate and blocked with $10 \%$ goat serum. Up to $0.25 \mathrm{~mL}$ of anti-Tau antibody (Abcam, 1:500) was added to each chamber, followed by incubation with goat anti-rabbit secondary antibody (Alexa Fluor 488, Abcam, UK). Axons were identified based on morphological characteristics. In live images, branches that are longer and with thin and uniform diameter, as well as sparse branching, were considered to be axons. Particles with strong red fluorescence (compared with background) and clear edges colocalized with axons were considered to be mitochondria. Fluorescence images were captured using a laserscanning confocal microscope (TCS-SPE, Leica, Germany) and analyzed using NIH ImageJ program.

\section{Recording and Analysis of Axonal Mitochondrial Trafficking}

MitoTracker Green (Thermo Fisher Scientific, Waltham, MA, USA) was used to label the mitochondria in living neurons. The axons and mitochondria were identified using the procedure described in Section Axonal Mitochondrial Density Assay and Length Measurement. The proximal region of axons was selected for time-lapse imaging analysis. Time-lapse images were captured under an inverted laser-scanning confocal microscope (TCS-SPE, Leica, Germany) with a stage-based chamber under $5 \% \mathrm{CO}_{2}$ and $37^{\circ} \mathrm{C}$. Time-lapse image stacks composed of five images $(512 \times$ 512 pixel) were taken every $10 \mathrm{~s}$ for $5 \mathrm{~min}$ for a total of 150 images under $40 \times$ magnification. Kymographs were generated using the kymograph tool for ImageJ program under maximum intensity projection. The width of the kymographs represents the length $(\mu \mathrm{m})$ of the imaged axon, and the height represents the 
recording time. A mitochondrion was considered to be stationary if it remained non-mobile for the entire recording period. A mitochondrion was considered movable only if the displacement was more than $2 \mu \mathrm{m}$. The percentages of stationary and movable mitochondria and of anterograde and retrograde mitochondrial movement were measured separately from the corresponding kymographs by using NIH ImageJ program. A mitochondrion that moves from the soma toward the distal end of an axon is considered anterograde, whereas movement from the distal end toward the soma is considered retrograde. The average velocity $(\mu \mathrm{m} / \mathrm{s})$ of all anterograde and retrograde axonal mitochondria was calculated using the displacement of each mitochondrion.

\section{Dendritic Spine Density Measurement and Morphological Assay}

Neurons cultured in glass-bottom dishes with four chambers (CELLview, Greiner, Germany) were fixed in $4 \%$ paraformaldehyde for $20 \mathrm{~min}$ and washed with PBS after the neurons were incubated with $2 \mu \mathrm{M}$ preheated CellTracker CMDiI (Life Technologies, Waltham, MA, USA) for $20 \mathrm{~min}$ at $37^{\circ} \mathrm{C}$. LAS X software was used to control the laser-scanning confocal microscope (TCS-SPE, Leica, Germany) equipped with a $63 \times$ objective and excitation at $543 \mathrm{~nm}$. Images were taken under the confocal microscope, and Z-stacks were gathered at increments of $0.67 \mu \mathrm{m}$. To increase the accuracy of the identification of the surfaces of the dendrite shaft and spines, sequence images were deconvolved to reduce point-spread functions by using the adaptive blind 3D deconvolution method (AutoQuant X, Media Cybermedics, Inc., Bethesda, MD) prior to analysis. The output images were obtained with Build Neurites and Build Spines in NeuronStudio software (CNIC, Mt. Sinai School of Medicine, New York, USA) to mark and record all the spines on the selected dendrites. Dendritic protrusions with a clearly identifiable neck attached to the branch of the dendrite composed a spine. The output data included length, neck diameter, and head diameter of each spine, based on which the types of spines were recognized. Spines with a spine length-to-neck diameter ratio $<2.0$ were defined as of the stubby type. Spines were categorized as mushroom type if they presented a length-to-neck diameter ratio of more than 2.0 and a head-to-neck diameter ratio of more than 1.3. Spines were categorized as thin type if the spines exhibited a length-to-neck diameter ratio of more than 2.0 and a head-to-neck diameter ratio of $<1.3$ (Du et al., 2014). Spine density and morphology were measured separately for portions of three to five selected secondary dendrites per neuron.

\section{Neuronal Synaptic Density Analysis}

Cultured hippocampal neurons were fixed in $4 \%$ paraformaldehyde for $20 \mathrm{~min}$ after the neurons were permeabilized with $0.5 \%$ Triton X-100 in $0.1 \%$ sodium citrate and blocked with $10 \%$ goat serum. Up to $0.25 \mathrm{~mL}$ each of anti-MAP2 antibody (Abcam, 1:100) and anti-synaptophysin (Abcam, 1:200) was added to each chamber, followed by incubation with goat anti-rabbit and mouse secondary antibodies (Alexa Fluor 488, Alexa Fluor 594, Abcam, UK) for $30 \mathrm{~min}$ at $37^{\circ} \mathrm{C}$. Images were taken under a laser-scanning confocal microscope (TCS-SPE, Leica, Germany) by using a $40 \times$ objective and excitation of 488 and $543 \mathrm{~nm}$, and Z-stacks were gathered at increments of 0.67 $\mu \mathrm{m}$. The $z$-stack images were compressed to a single image via the max projection method and analyzed using NIH ImageJ program.

\section{Statistical Analysis}

The results were processed for statistical analysis using SPSS (version 20.0 for Windows). The results are presented as the mean \pm standard error of the mean (SEM). Statistical analyses were performed with one-way analysis of variance, followed by Fisher's protected least significant difference test for post-hoc comparisons. A value of $P<0.05$ was considered significant.

\section{RESULTS}

\section{Geniposide Ameliorated $A \beta_{1-42}$-Induced Axonal Mitochondrial Abnormalities}

Mitochondria are vital to the function of synapses because they supply energy for maintenance, calcium buffering, synaptic transmission, and vesicle release. Mitochondria are thought to be synthesized perinuclearly. Thus, they must be transferred from the soma to distal synapses through axons and dendrites via mitochondrial transport and constantly reconfigured to meet synaptic needs. Mitochondrial morphology is also dynamic and can be regulated through fusion and fission. An elongated morphology may confer bioenergetic advantages for ATP generation and dispersal (Skulachev, 2001). Therefore, the effects of geniposide on $A \beta$-induced abnormal axonal mitochondrial trafficking, distribution, and morphology were analyzed. A primary cultured hippocampal neuronal model was examined as previously reported because of the technical limitations on observing mitochondrial trafficking in vivo (Du et al., 2010). Axonal processes were selected for the quantitative analysis of mitochondrial length, density, distribution, and mobility because of their known morphologic and dynamic characteristics (Banker and Cowan, 1979; Du et al., 2010) and because of the significantly synaptic pathology of $\mathrm{AD}$.

\section{Geniposide Attenuated $A \beta_{1-42}$-Induced Axonal Mitochondrial Fragmentation}

First, axonal mitochondrial density was evaluated by counting the mitochondria (particles positive for MitoTracker Red) in each axonal process of the same length. As shown in Figures 1A,B, the axonal mitochondrial density was significantly lower $(\sim 37 \%)$ in neurons treated with $\mathrm{A} \beta_{1-42}$ than in vehicle-treated neurons $(2.685 \pm 0.237$ vs. $1.685 \pm 0.181$ per $10 \mu \mathrm{m} ; p<0.01)$. However, the axonal mitochondrial density of neurons pretreated with $10 \mu \mathrm{M}$ geniposide was significantly higher than that of neurons treated with $A \beta_{1-42}$ alone $(2.611 \pm 0.217$ vs. $1.685 \pm 0.181$ per $10 \mu \mathrm{m} ; p<0.01)$.

Second, the changes in mitochondrial morphology were detected by measuring the axonal mitochondrial length. Treatment with $200 \mathrm{nM}$ oligomeric $\mathrm{A} \beta_{1-42}$ significantly decreased the average length of axonal mitochondria compared with hippocampal neurons treated with vehicle or geniposide (1.117 $\pm 0.049 \mu \mathrm{m}$ in $\mathrm{A} \beta_{1-42}$-treated neurons vs. $1.435 \pm$ $0.041 \mu \mathrm{m}$ in vehicle-treated neurons or $1.375 \pm 0.023 \mu \mathrm{m}$ in 

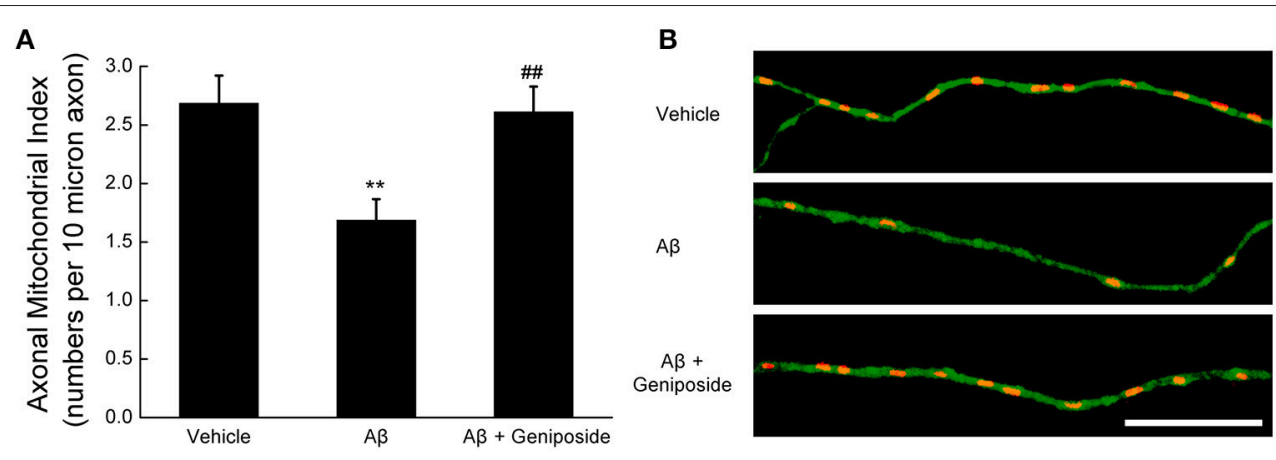

C

D
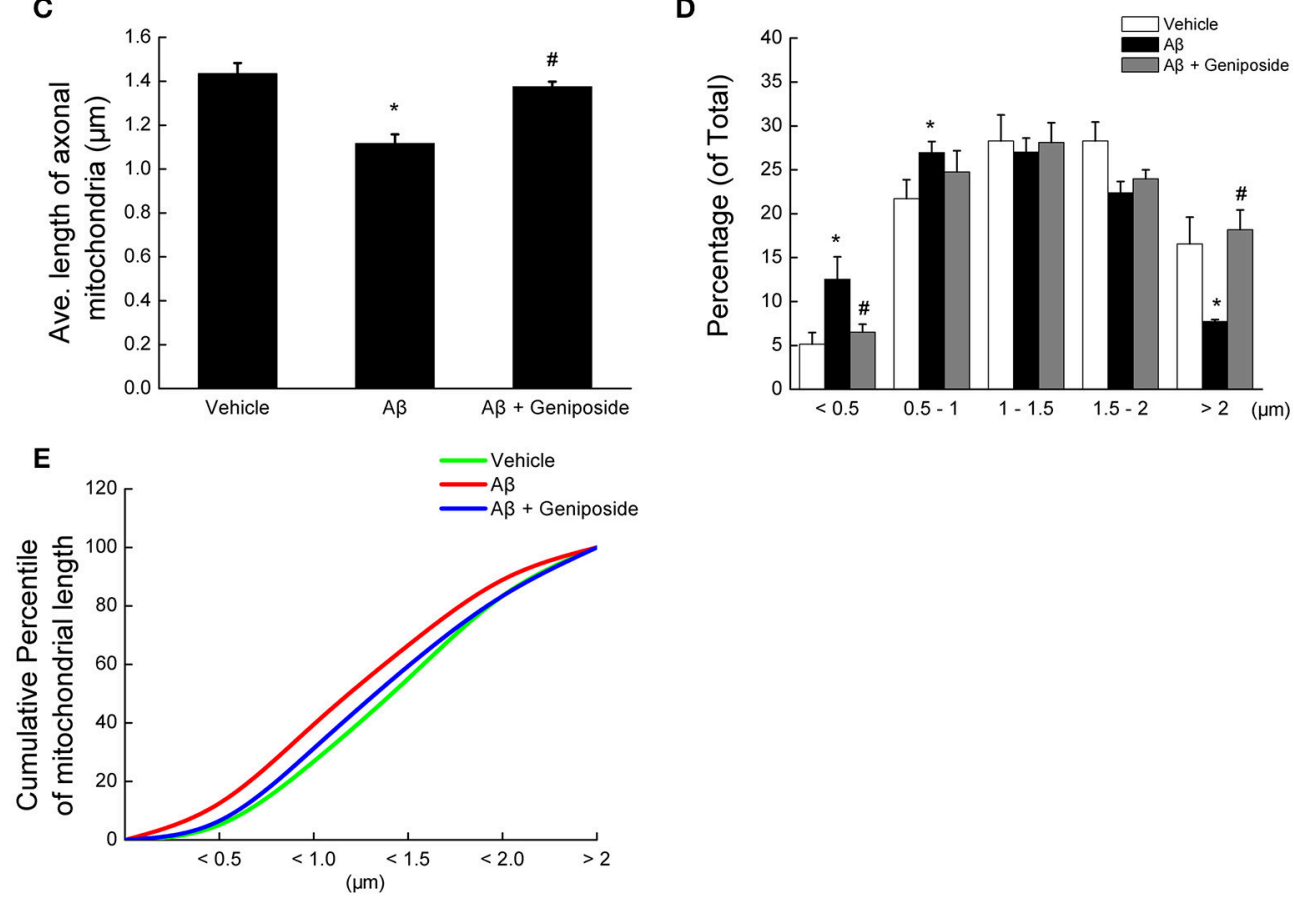

FIGURE 1 | Geniposide ameliorated the reduction in axonal mitochondrial density and length induced by oligomeric $A \beta_{1-42}$ treatment. (A) $A x o n a l$ mitochondria from hippocampal neurons (14 DIV) were analyzed after $24 \mathrm{~h}$ of treatment with vehicle, oligomeric $A \beta_{1-42}(200 \mathrm{nM})$, or oligomeric $A \beta_{1-42}+$ geniposide $(10 \mu \mathrm{M})$. The axonal mitochondrial index (numbers per $10 \mu \mathrm{m}$ of axon) was computed from three independent experiments. ${ }^{* *} p<0.01$ vs. vehicle-treated group, $\# \# p<0.01$ vs. $A \beta$-treated group. (B) Representative images of axonal mitochondrial distribution for the groups treated with vehicle, oligomeric $A \beta_{1-42}$, or oligomeric $\mathrm{A} \beta_{1-42}+$ geniposide. Double fluorescent staining with MitoTracker Red (red, mitochondrial marker) and Tau (green, axonal marker) was performed. Scale bar $=10$ $\mu \mathrm{m}$. (C) Average lengths of axonal mitochondria in the three groups. ${ }^{*} p<0.05$ vs. vehicle-treated group, $\#_{p}<0.05$ vs. A -treated group. (D) Distribution of axonal mitochondrial length in the three groups. (E) Cumulative percentile of mitochondrial length in C. $n=3$ independent cultures, eight axons per group.

geniposide- and $\mathrm{A} \beta_{1-42}$-treated neurons; $p<0.05$; Figure 1C). The percentage of axonal mitochondria $<0.5 \mu \mathrm{m}$ in length in neurons exposed to $A \beta$ was significantly higher than in neurons treated with vehicle or geniposide (Figure 1D), whereas the percentage of mitochondria more than $2.0 \mu \mathrm{m}$ long decreased. Cumulative data indicated a leftward shift in the mitochondrial length of $A \beta_{1-42}$-treated neurons (Figure 1E).

\section{Geniposide Ameliorated the $A \beta_{1-42}$-Induced Impairment of Axonal Mitochondrial Trafficking}

Third, mitochondrial trafficking within hippocampal axonal processes was investigated. The percentage of stationary mitochondria among total mitochondria in $\mathrm{A} \beta_{1-42}$-treated neurons was significantly higher (by $\sim 15 \%$ ) that that in the neurons treated with vehicle $(60.028 \pm 2.154$ vs. $74.695 \pm 3.363 \%$; $p<0.01$, Figure 2A), and geniposide treatment produced a partial recovery of the percentage of stationary mitochondria (63.319 $\pm 2.761 \% ; p<0.05$; Figure 2A). The percentage of mitochondria moving in either direction (anterograde and retrograde) in $A \beta_{1-42}$-treated neurons was significantly lower than in vehicle-treated and geniposide-treated neurons (Figures 2A,C). The percentage of anterograde mitochondria among movable mitochondria in $A \beta_{1-42}$-treated neurons slightly decreased compared with neurons treated with vehicle or geniposide ( $45.63 \pm 2.324 \%$ in $A \beta_{1-42}$-treated neurons vs. 56.3 $\pm 3.24 \%$ in vehicle-treated neurons or $56.55 \pm 3.323 \%$ in 

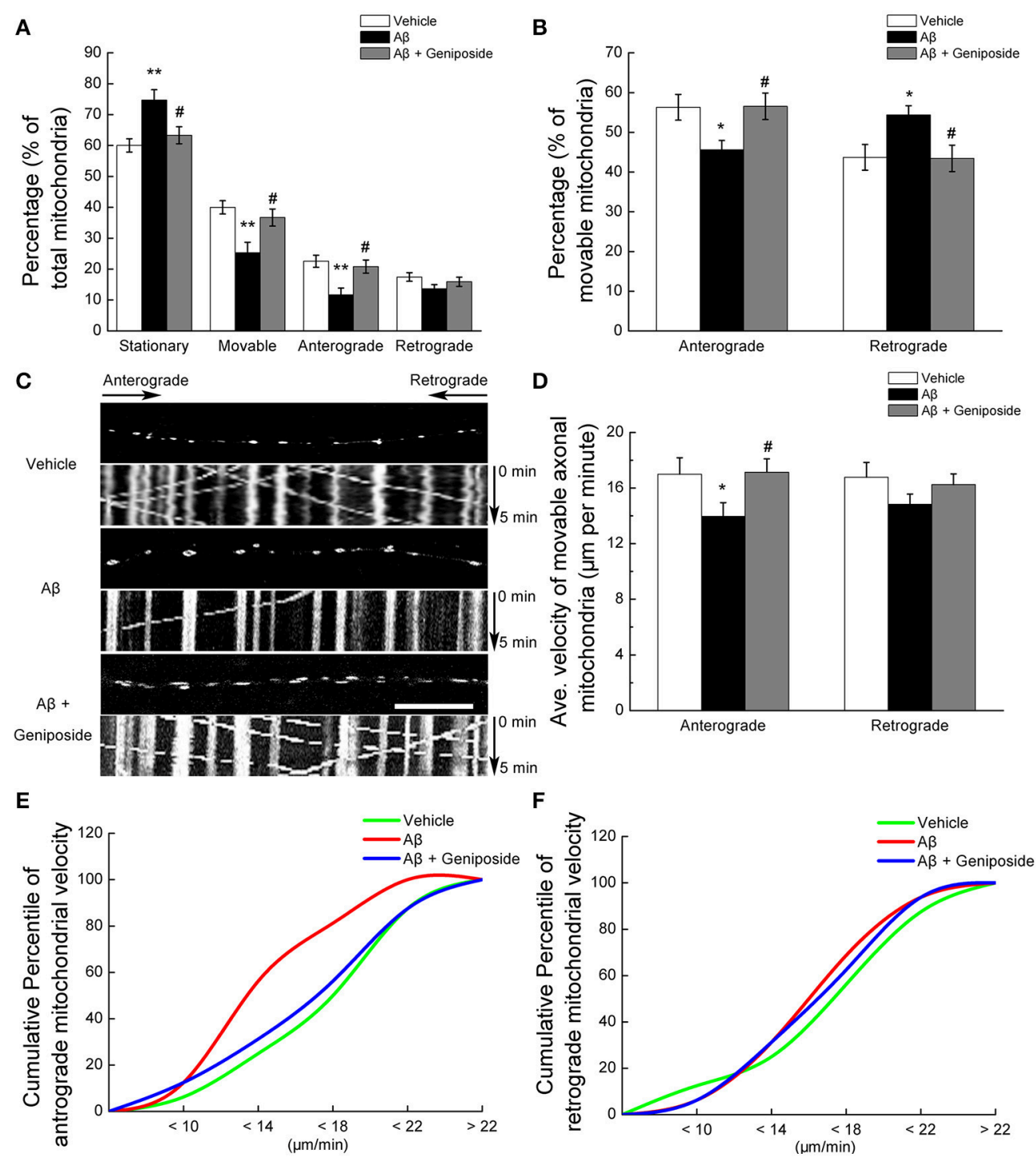

FIGURE 2 | Geniposide ameliorated the abnormal axonal trafficking of mitochondria induced by oligomeric $\mathbf{A} \boldsymbol{\beta}_{\mathbf{1}-42}$ treatment. Axons from hippocampal neurons at 14 DIV were analyzed after $24 \mathrm{~h}$ of treatment with vehicle, oligomeric $A \beta_{1-42}(200 \mathrm{nM})$, or oligomeric $A \beta_{1-42}+$ geniposide (10 $\left.\mu \mathrm{M}\right)$. Fluorescent staining with MitoTracker Green (mitochondrial marker) was performed. (A) Percentages of stationary, movable, anterograde-moving, and retrograde-moving mitochondria were calculated compared with the numbers of total mitochondria. ${ }^{* *} p<0.01$ vs. vehicle-treated group, $\# p<0.05$ vs. A $\beta$-treated group. (B) Percentages of anterograde-moving and retrograde-moving mitochondria were calculated compared with the total numbers of movable mitochondria. ${ }^{\star} p<0.05$ vs. vehicle-treated group, ${ }^{\#} p<0.05$ vs. A -treated group. (C) Calculations were based on analysis of kymographs. Representative kymographs of the axonal mitochondrial movement in the three experimental groups. Scale bar $=10 \mu \mathrm{m}$. (D) Average velocity of anterograde and retrograde transport of mitochondria for all movable mitochondria ( $\mu \mathrm{m} / \mathrm{min}$ ) is shown. ${ }^{*} p<0.05$ vs. vehicle-treated group, $\# p<0.05$ vs. A $\beta$-treated group. (E,F) Cumulative percentile of anterograde or retrograde mitochondrial velocity in D. $n=4$ independent cultures, six axons per group.

geniposide- and $\mathrm{A} \beta_{1-42}$-treated neurons; $p<0.05$; Figure 2B). By contrast, the percentage of retrograde mitochondria increased in $\mathrm{A} \beta_{1-42}$-treated neurons.

Fourth, the velocity of mitochondrial movement within axons was measured. $\mathrm{A} \beta_{1-42}$ treatment produced a greater detrimental effect on anterograde mitochondrial movement velocity than retrograde (Figure 2D). $\mathrm{A} \beta_{1-42}$ treatment decreased the anterograde velocity of axonal mitochondria by $18 \%\left(16.996 \pm 1.18 \mu \mathrm{m} / \mathrm{min}\right.$ in $\mathrm{A} \beta_{1-42}$-treated neurons vs.
$13.965 \pm 0.98 \mu \mathrm{m} / \mathrm{min}$ in vehicle-treated neurons; $p<0.05$; Figures 2D,E), whereas the geniposide treatment decreased the toxicity of $\mathrm{A} \beta_{1-42}$ on the anterograde mitochondrial velocity $\left(16.996 \pm 1.18 \mu \mathrm{m} / \mathrm{min}\right.$ in $\mathrm{A} \beta_{1-42}$-treated neurons vs. 17.134 $\pm 0.961 \mu \mathrm{m} / \mathrm{min}$ in geniposide- and $A \beta_{1-42}$-treated neurons; $p$ $<0.05)$. However, the retrograde transport velocity of axonal mitochondria did not differ significantly among the three groups (Figures 2D,F). Cumulative data displayed a leftward shift in the anterograde mitochondrial velocity (Figure 2E) but not in the 
retrograde mitochondrial velocity (Figure 2 F) of $A \beta_{1-42}$-treated neurons.

\section{Geniposide Attenuates $A \beta_{1-42}$-Induced Neurites ROS Elevation}

The mitochondrial ROS level was evaluated by measuring the fluorescence intensity of DCF within neurites. As shown in Figures $3 A, B$, the fluorescence intensity of DCF within the neurites of $A \beta_{1-42}$-treated hippocampal neurons significantly increased (by $\sim 48 \%$ ), unlike the vehicle-treated or geniposidetreated neurons $\left(1.0 \pm 0.075\right.$ in $A \beta_{1-42}$-treated neurons vs. $1.478 \pm 0.097$ in vehicle-treated neurons or $1.050 \pm$ 0.065 in geniposide- and $\mathrm{A} \beta_{1-42}$-treated neurons; $p<0.01$; Figure 3B). These results suggested that geniposide treatment significantly reduced the $A \beta$-induced increase in ROS in neurite mitochondria.

These data indicate that geniposide plays a protective role against the increased mitochondrial fragmentation, ROS elevation, and defective axonal mitochondrial trafficking induced by oligomeric $A \beta_{1-42}$ in neurons.

\section{Geniposide Alleviated $A \beta_{1-42}$-Induced Synaptic Damage in Cultured Neurons and an AD Model}

Axonal mitochondria are dynamic organelles, and their dynamics, trafficking, and docking are critical to maintain synaptic function and plasticity. The impairment of axonal mitochondrial may lead to synaptic loss and dysfunction. Various lines of evidence indicate that synaptic loss and deactivation are the biological bases of $\mathrm{AD}$, and the accumulation of $\mathrm{A} \beta$ is an early event associated with synaptic and mitochondrial damage in $\mathrm{AD}$. Thus, the density of synapses, the morphology of dendritic spines, and the levels of synapse-related proteins were analyzed to assess the contributions of abnormal mitochondrial fragmentation and trafficking to synaptic loss and dysfunction.

\section{Geniposide Protected against $A \beta_{1-42}$-Induced Synaptic Loss}

Synaptic density was measured by counting synaptophysinpositive clusters (green) on dendrites in order to determine the protective effect of geniposide on oligomeric $A \beta_{1-42}$-induced synaptic loss. As shown in Figure $\mathbf{4 A}$, there were significantly fewer synaptophysin-positive clusters in $A \beta$-treated neurons than in vehicle- or geniposide-treated neurons. The density of synapses in $A \beta_{1-42}$-treated neurons was significantly lower (by $\sim 49 \%)$ than in the vehicle-treated neurons (1.001 \pm 0.041 per micron vs. $0.509 \pm 0.030$ per micron; $p<0.001$, Figure 4B), whereas neurons pre-treated with geniposide $(10 \mu \mathrm{M})$ showed a higher density of synapses than the $A \beta_{1-42}$-treated group (0.985 \pm 0.040 per micron vs. $0.509 \pm 0.030$ per micron; $p<0.001$ ).

\section{Geniposide Rescued $A \beta_{1-42}$-Induced Abnormal Spine Density and Morphology}

Dendritic spine density and morphology significantly changed in transgenic AD mouse models (Perez-Cruz et al., 2011; Penazzi et al., 2016); therefore, the spine phenotypes in cultured primary hippocampal neurons were investigated using CellTracker CMDiI, and dendritic spines were categorized into three groups (mushroom, stubby, and thin).

First, the spine density was examined. As expected, $\mathrm{A} \beta_{1-42}$ treatment significantly decreased the spine density on dendrites, whereas geniposide-treated neurons showed notable recovery (7.95 \pm 0.405 per $10 \mu \mathrm{m}$ in $\mathrm{A} \beta_{1-42}$-treated neurons vs. 10.825 \pm 0.994 per $10 \mu \mathrm{m}$ in vehicle-treated neurons or $10.575 \pm$ 0.826 per $10 \mu \mathrm{m}$ in geniposide- and $\mathrm{A} \beta_{1-42}$-treated neurons; $p<0.05$; Figure 5A). Cumulative data showed a substantial leftward shift in the spine density of $A \beta_{1-42}$-treated neurons (Figure 5B).

Subsequently, the spine morphology was evaluated in terms of spine length and classification (mushroom, stubby, and thin). The morphology of the spines from $A \beta_{1-42}$-treated neurons changed markedly from that of vehicle-treated neurons: the former appeared shorter and more stubby, with fewer
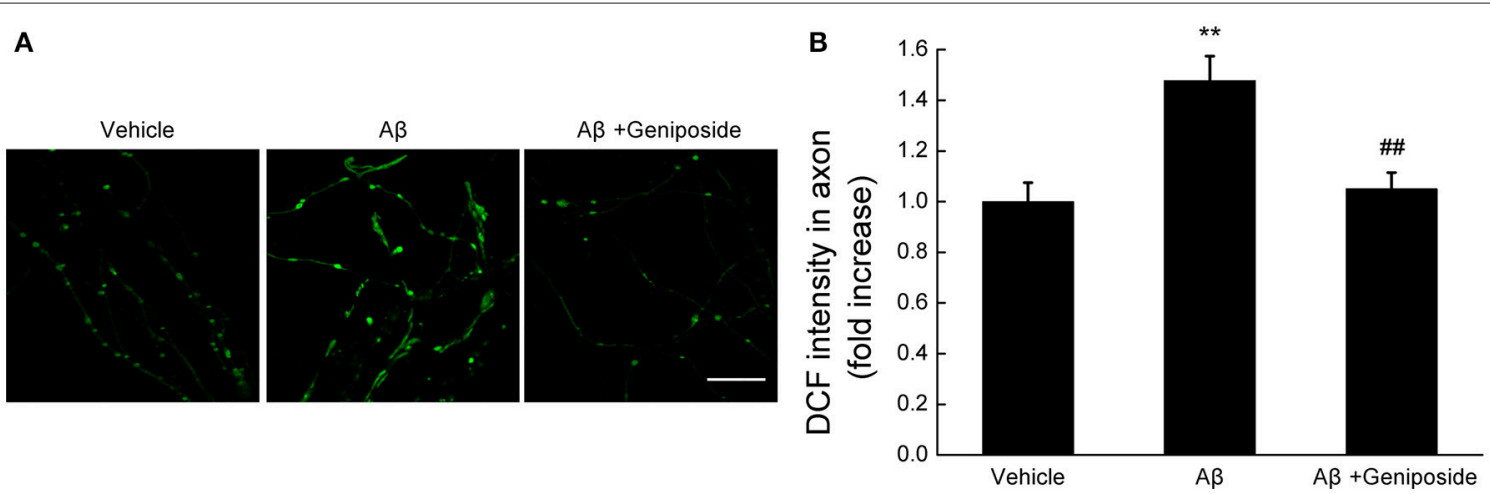

FIGURE 3 | Geniposide treatment attenuates the oligomeric A $\boldsymbol{\beta}$-induced increase in neuritic ROS. (A) Representative images of DCF staining of hippocampal neurites treated with vehicle, oligomeric $A \beta_{1-42}(200 \mathrm{nM})$, or oligomeric $\mathrm{A} \beta_{1-42}+$ geniposide $(10 \mu \mathrm{M})$. Scale bar $=10 \mu \mathrm{m}$. (B) Quantification of $\mathrm{DCF}$ intensity in (A). The intensity of DCF-labeled neurites was significantly increased in neurons treated with oligomeric $A \beta_{1-42}$ for $24 \mathrm{~h}$, while the geniposide treatment dramatically reduced the $A \beta$-induced ROS elevation. ${ }^{* *} p<0.01$ vs. vehicle-treated group, $\# \# p<0.01$ vs. A $\beta$-treated group. $n=4$ independent cultures. 
A

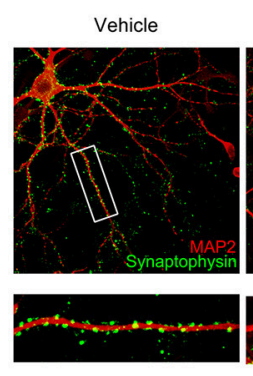

$A B$

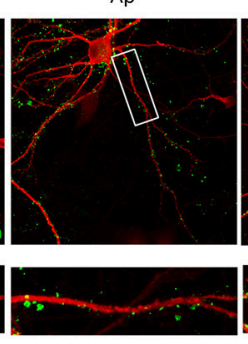

$A \beta+$ Geniposide

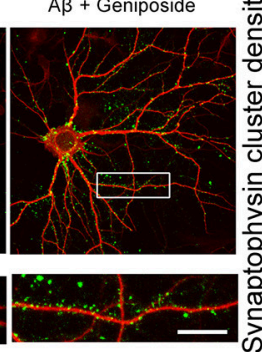

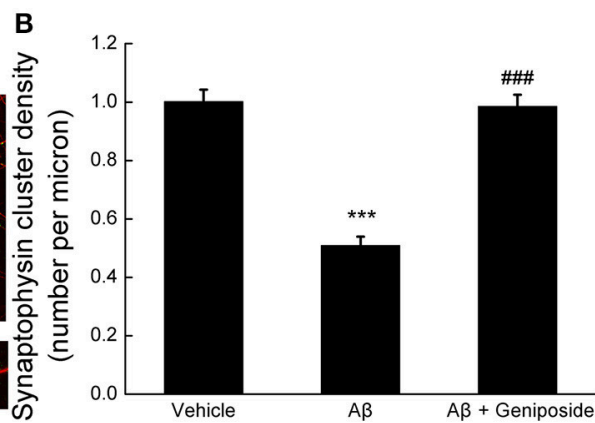

FIGURE 4 | Effect of geniposide on A $\beta$-induced synaptic loss. Cultured hippocampal neurons at 14 DIV were analyzed after 24 h of treatment with vehicle, oligomeric $A \beta_{1-42}(200 \mathrm{nM})$, or oligomeric $A \beta_{1-42}+$ geniposide $(10 \mu \mathrm{M})$. Immunostaining with MAP2 (neuronal marker) and synaptophysin (synaptic marker) was

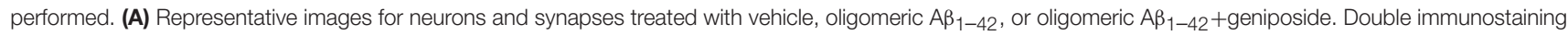
with MAP2 and synaptophysin. Scale bar $=10 \mu \mathrm{m}$. (B) Numbers of synaptophysin-positive clusters per micron of dendrites were significantly increased in $\mathrm{A} \beta_{1-42}+$ geniposide-treated neurons compared with $\mathrm{A} \beta_{1-42}$-treated neurons. ${ }^{\star \star \star} p<0.001$ vs. vehicle-treated group, $\# \# \# p<0.001$ vs. $A \beta$-treated group. $n=4$ independent cultures, eight neurons per group.

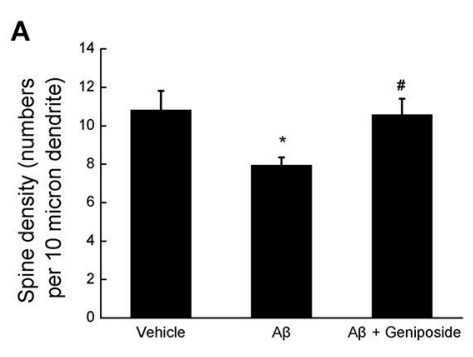

D

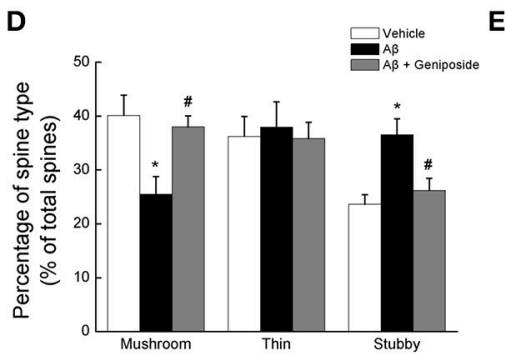

G

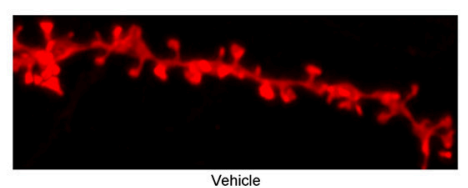

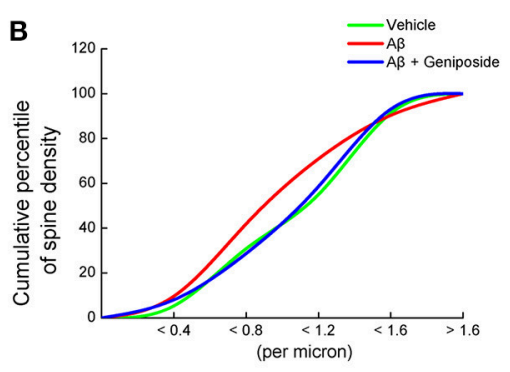

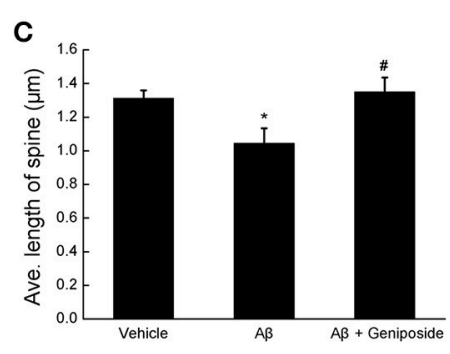

E
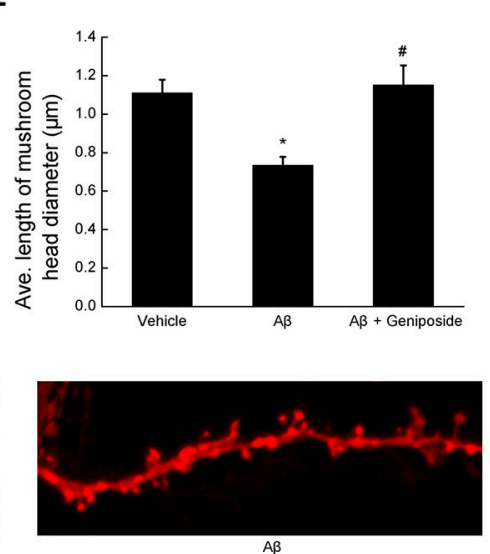
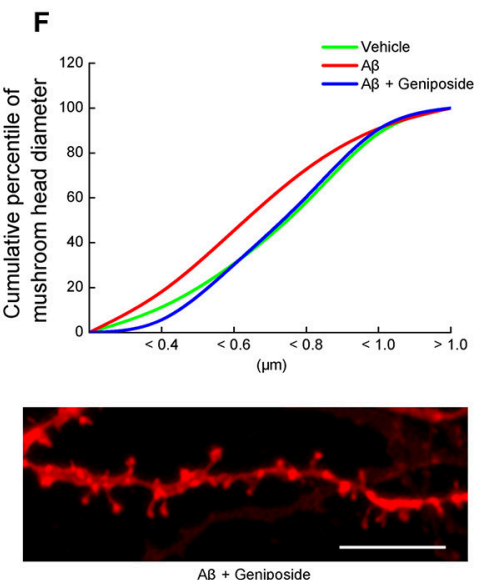

FIGURE 5 | Geniposide rescued the $\mathbf{A} \boldsymbol{\beta}_{\mathbf{1}} \mathbf{- 4 2}$-induced abnormal spine density and morphology. Dendrites from hippocampal neurons at 14 DIV were analyzed after $24 \mathrm{~h}$ of treatment with vehicle, oligomeric $A \beta_{1-42}(200 \mathrm{nM})$, or oligomeric $\mathrm{A} \beta_{1-42}+$ geniposide $(10 \mu \mathrm{M})$. Fluorescent staining with CellTracker CM-Dil was performed. (A) Quantification of total spine density per $10 \mu \mathrm{m}$ of dendrite. (B) Cumulative percentile of spine density in (A). (C) Average lengths of all spines in the three groups. (D) Percentages of the three spine types (mushroom, thin, and stubby) in total spines. (E) Average head diameter of mushroom spines. (F) Cumulative percentile of mushroom head diameter in (E). (G) Representative images of Dil-labeled dendritic segments. Scale bar $=5 \mu \mathrm{m}$. ${ }^{\star} P<0.05$ vs. vehicle-treated group, $\# p<0.05$ vs. A $\beta$-treated group. $n=4$ independent cultures, eight neurons per group.

mushroom-type spines than the latter (Figure 5G). Calculation of the average length of spines showed that $A \beta_{1-42}$ treatment significantly decreased the spine length (by $\sim 20 \%$ ), whereas geniposide treatment reversed this pattern (Figure 5C). The quantitative analysis of dendritic spines in $\mathrm{A} \beta_{1-42}$-treated neurons showed that the percentage of mushroom-like spines significantly decreased $\left(25.476 \pm 3.308 \%\right.$ in $\mathrm{A} \beta_{1-42}$-treated neurons vs. $40.129 \pm 3.776 \%$ in vehicle-treated neurons or 37.977 $\pm 2.052 \%$ in geniposide- and $A \beta_{1-42}$-treated neurons; $p<0.05$; Figures 5D,G), but the percentage of stubby-like spines increased $\left(36.548 \pm 2.957 \%\right.$ in $\mathrm{A} \beta_{1-42}$-treated neurons vs. $23.641 \pm 1.755 \%$ in vehicle-treated neurons or $26.206 \pm 2.268 \%$ in geniposide- 
and $A \beta_{1-42}$-treated neurons; $p<0.05$; Figures 5D,G). However, pretreatment with geniposide almost completely reversed the deleterious effect of $A \beta_{1-42}$ on the percentages of stubby and mushroom spines. Geniposide considerably increased the average mushroom head diameter compared with $A \beta_{1-42}$-treated neurons $(1.152 \pm 0.102$ vs. $0.735 \pm 0.043 \mu \mathrm{m} ; p<0.05$; Figure 5E). The plots of cumulative percentage curves clearly displayed a leftward shift in the mushroom head diameter of $A \beta_{1-42}$-treated neurons (Figure 5F). These data indicated that geniposide treatment significantly preserved dendritic spine density and morphology, which may play a protective role in synaptic function.

\section{Geniposide Ameliorated the Decrease in Synapse-Related Proteins in Cultured Neurons and Mice}

Synaptic plasticity is widely thought to be the basis of learning and memory formation. Synapse-related proteins are the foundation of synaptic plasticity. To investigate the effect of geniposide on the expression of synapse-related proteins, the levels of specific synaptic proteins in cultured primary hippocampal neurons were examined. The levels of synapse-related proteins significantly decreased in $A \beta_{1-42-}$ treated neurons relative to vehicle-treated neurons. As shown in Figure 6, the levels of p-CaMKII $\alpha / \mathrm{CaMKII} \alpha$, p-CREB/CREB, synaptophysin, and PSD-95 in $A \beta_{1-42}$-treated neurons were markedly lower than those in vehicle-treated neurons and significantly increased in neurons treated with various doses of geniposide (2.5, 5.0, and $10.0 \mu \mathrm{M}$ geniposide; Figure 6). The expression of synapse-related proteins in the hippocampi of C57 and APP/PS1 (overexpressing A $\beta$ ) mice was examined further. Consistent with the data in cultured neurons, these results showed that the expression levels of p-CaMKII/CaMKII $\alpha$, p-CREB/CREB, synaptophysin, and PSD-95 were lower in vehicle-treated APP/PS1 mice than in vehicle-treated WT mice. Geniposide treatment $(12.5,25$, and $50 \mathrm{mg} / \mathrm{kg})$ of APP/PS1 mice also significantly increased the levels of the above proteins in a dose-dependent manner (Figure 7). These data indicate that the application of geniposide protects the expression of synapserelated proteins against the neurotoxic effects of $A \beta$ in neurons and APP/PS1 mice.

\section{DISCUSSION}

There are evidence suggest that geniposide have multifaceted neuroprotective effects, such as ameliorating cholinergic deficit (Zhao et al., 2016b), increasing the expression of insulindegrading enzyme (Zhang et al., 2015) and attenuating $A \beta$ accumulation (Lv et al., 2015), inhibiting the signaling pathway of RAGE-MAPK and suppressing the production of proinflammatory mediators (Lv et al., 2014b, 2015), and protecting mitochondria by recovering ATP generation and mitochondrial membrane potential (Lv et al., 2014a; Zhao et al., 2016a). However, the protective effect of geniposide on $A \beta$ induced mitochondrial transport and synaptic injury remains unclear.
The protective effect of geniposide against oligomeric $A \beta_{1-42}$ in primary cultured hippocampal neurons was investigated in the current study. In consideration of the influence of overproduction of amyloid precusor protein (APP) and its metabolites in APP transgenic mice's neurons, we investigated the toxicity effect of $A \beta$ by adding exogenous oligomeric $A \beta_{1-42}$. Evidence suggests that RAGE mediates the transport of $\mathrm{A} \beta$ peptides across the cytomembrane from extracellular to intracellular (Deane et al., 2003; Takuma et al., 2009; Candela et al., 2010), including mitochondrial localization. Moreover, $A \beta$ can be transported to the mitochondria via the TOM machinery and ER-mitochondrial crosstalk (Hansson Petersen et al., 2008; Hedskog et al., 2013).

In the present study, we demonstrate that geniposide protects cultured primary hippocampal neurons from the $A \beta$-induced impairment of axonal mitochondrial transport by improving axonal mitochondrial morphology, motility, and distribution, as well as rescuing anterograde mitochondrial movement, thus alleviating $\mathrm{A} \beta$-induced synaptic injury by increasing the numbers of synapses and dendritic spines and the levels of synapse-related proteins, as well as attenuating the increase in ROS.

Axonal mitochondrial transport and synaptic mitochondrial distribution play crucial roles in synaptogenesis, synaptic transmission, and synaptic plasticity (Chang et al., 2006). Abnormal synaptic mitochondrial mobility and dynamics are responsible for synaptic failure. Considering the critical role of synaptic failure and neuronal dysfunction in $\mathrm{AD}$ pathogenesis, studies have investigated the mechanisms of synaptic mitochondrial perturbation that contribute to synaptic dysfunction (Du et al., 2008, 2010). These studies indicated that $\mathrm{A} \beta$-induced abnormal axonal mitochondrial trafficking and synaptic mitochondrial dysfunction are responsible for the synaptic injury in $\mathrm{AD}$.

Presynaptic terminals require mitochondria to handle calcium buffering, power the plasma membrane $\mathrm{Ca}^{2+}$-ATPase, and release $\mathrm{Ca}^{2+}$ to maintain post-tetanic potentiation (Medler and Gleason, 2002). Furthermore, synthesis of neurotransmitters, release of synaptic vesicles, outgrowth of axonal, and maintenance of synaptic plasticity also need mitochondria to supply high levels of ATP (Dillon and Goda, 2005). Therefore, decreased mitochondrial transport in axons likely impairs the delivery of organelles to synapses. $A \beta$ has been reported to cause rapid and severe impairment of synaptic mitochondrial distribution and axonal mitochondrial mobility and thus to increase axonal mitochondrial fragmentation (Rui et al., 2006; Du et al., 2010; Calkins et al., 2011; Manczak et al., 2011). The current results regarding mitochondrial morphology and mobility indicated that geniposide ameliorated the effects of $\mathrm{A} \beta$ treatment that were induced by abnormal mitochondrial morphology and trafficking in axons by increasing the mitochondrial density and length and the proportions of movable and anterograde-transported mitochondria, as well as the average velocity of movable axonal mitochondria. These data suggest that geniposide may protect synaptic mitochondrial function from $A \beta$-induced impairment at an early stage.

$A \beta$-induced axonal and synaptic mitochondrial dysfunction is accompanied by synaptic degradation and is exhibited as 

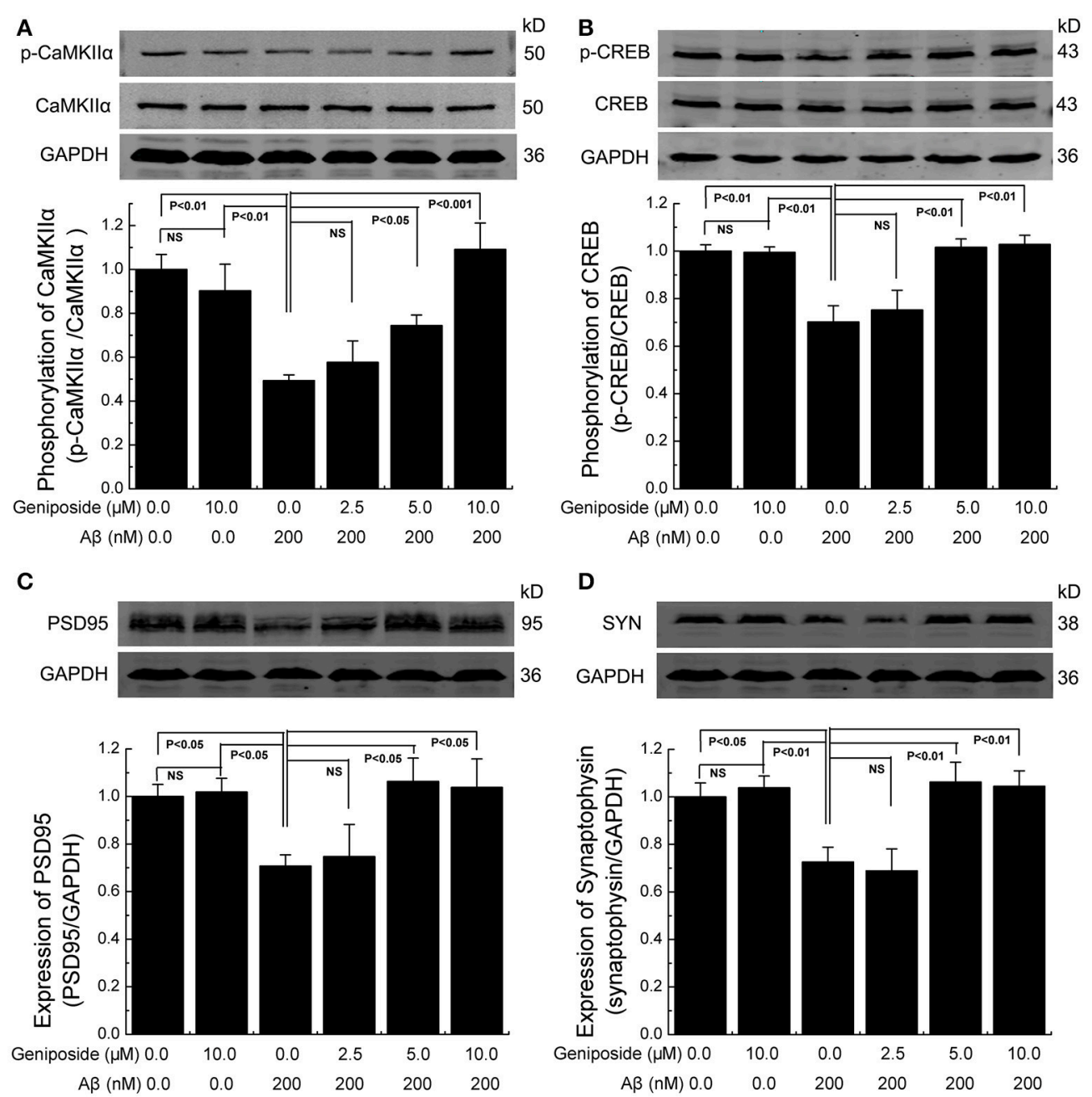

FIGURE 6 | Geniposide alleviated the decrease in synapse-related proteins in cultured primary hippocampal neurons. (A-D) Western blot analysis of phospho-CaMKIl $\alpha$ and total-CaMKIl $\alpha$ (A), phospho-CREB and total-CREB (B), PSD-95 (C), synaptophysin (SYN) (D), and GAPDH in hippocampal neurons treated with the indicated concentrations of oligomeric $A \beta_{1-42}$ or geniposide. Western blot of synaptophysin, PSD-95, and GAPDH were performed in the same membrane, therefore they share the same loading control (GAPDH). Quantification of p-CaMKIl $\alpha / C a M K I l \alpha(\mathbf{A})$ p-CREB/CREB (B), PSD-95/GAPDH (C), and

synaptophysin/GAPDH (D) was performed with the values from vehicle-treated neurons set as 1.0. Data are presented as the mean \pm SEM. $n=4$ independent cultures. NS, non-significant.

the decrease of synapse-related proteins, the loss of dendritic spines and synapses, and morphological changes to spines. Synapse-related proteins constitute the structural and functional foundation of synapses. However, the expression levels of synapse-related proteins, such as synaptophysin, PSD-95, pCaMKII, and p-CREB, are significantly decreased in the cortex and hippocampus of $\mathrm{AD}$ patients and of an $\mathrm{AD}$ mouse model (Gylys et al., 2004; Almeida et al., 2005; Zeng et al., 2015). Moreover, synaptic loss is the most severe condition of synaptic injury, and it manifests as the loss of dendritic spines and synapses in the brains of a transgenic $\mathrm{AD}$ mouse model and of $\mathrm{AD}$ patients. The density of dendritic spines significantly decreased in the cortex and hippocampus of several AD models (Yang et al., 2011; Du et al., 2014; Price et al., 2014), as well as in cultured primary hippocampal or cortical neurons treated with $\mathrm{A} \beta$ in vitro (Jo et al., 2011; Chen et al., 2015). In conclusion, the axonal and synaptic mitochondria are vulnerable and susceptible to various types of damage, leading to the synaptic degradation in AD. In the present study, geniposide-treatment significantly alleviated $\mathrm{A} \beta$-induced synaptic injury by protecting the expression levels of synapse-related proteins, the density of dendritic spines and synapses, and the morphology of spines. Similar results were obtained for the expression of synapse-related proteins in the hippocampi of APP/PS1 mice.

In summary, the results demonstrated that geniposide protected primary neurons from $A \beta$-induced oxidative stress and from the acute impairment of axonal mitochondrial trafficking and morphology. This protective effect is associated with structural and functional changes in synapses. These findings indicate that axonal and synaptic mitochondria are vulnerable and susceptible to injury by $\mathrm{A} \beta$ at a low concentration, whereas geniposide can alleviate such injury. Thus, geniposide is a 

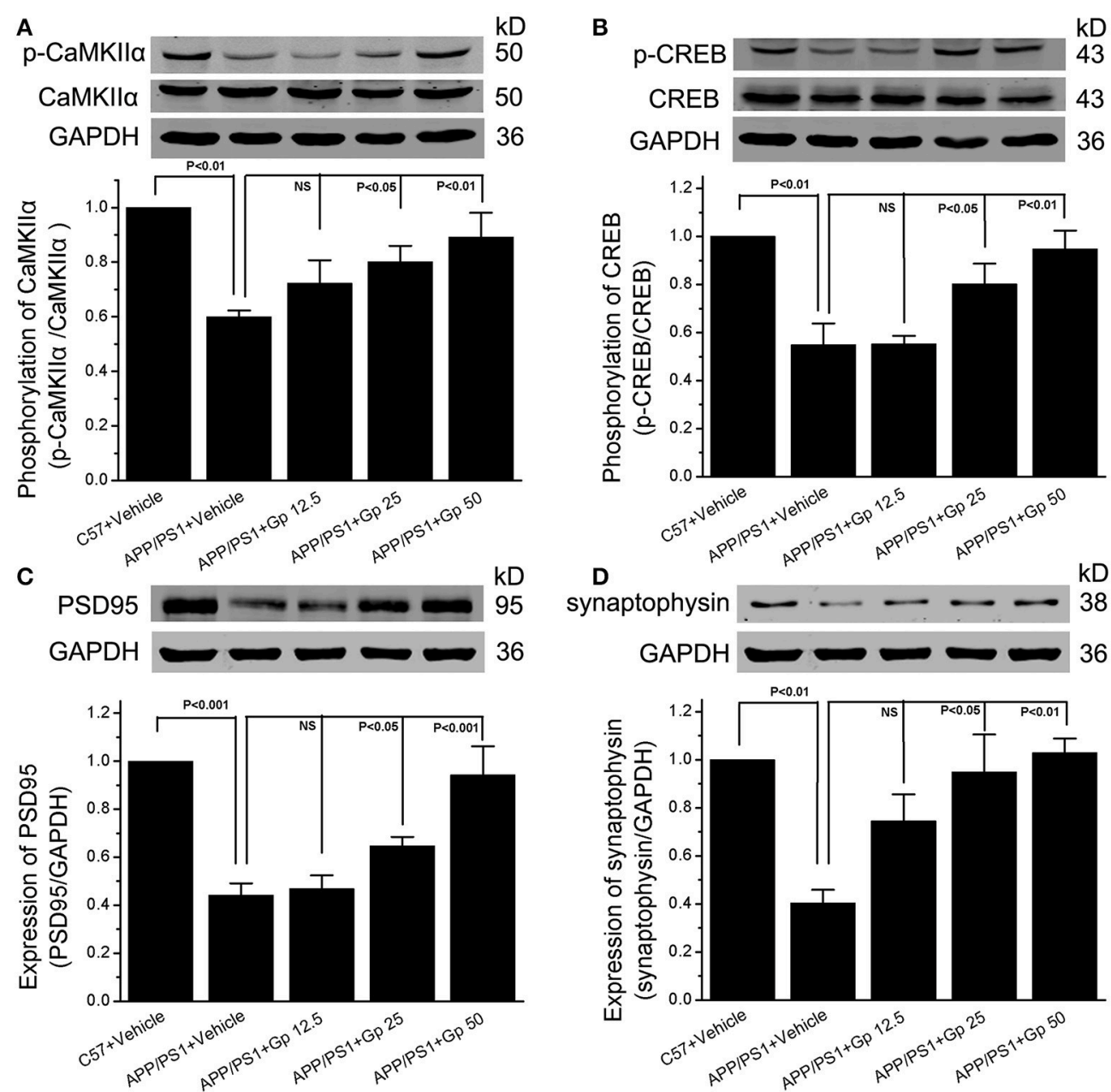

FIGURE 7 | Geniposide alleviated the decrease in synapse-related proteins in the hippocampi of APP/PS1 mice. (A-D) Western blot analysis of phospho-CaMKIl $\alpha$ and total-CaMKIl $\alpha$ (A), phospho-CREB, and total-CREB (B), PSD-95 (C), synaptophysin (D), and GAPDH in the hippocampi of indicated group of mice with/without geniposide administration. Western blot of synaptophysin, PSD-95 and GAPDH were performed in the same membrane, therefore they share the same loading control (GAPDH). Quantification of p-CaMKIl $\alpha / C a M K I l \alpha$ (A) p-CREB/CREB (B), PSD-95/GAPDH (C), and synaptophysin/GAPDH (D) was performed using the values from vehicle-treated WT mice as 1.0. Data are presented as the mean \pm SEM. $n=6$ mice for each group. Gp, mice treated with geniposide. NS, non-significant.

potential therapeutic agent that can be used to halt and prevent $\mathrm{AD}$ progression at an early stage.

\section{AUTHOR CONTRIBUTIONS}

$\mathrm{HZ}, \mathrm{CZ}, \mathrm{YW}$, and WZ designed the research; CZ, HZ, SD, CL, and $\mathrm{ZL}$ performed the research and analyzed data; and $\mathrm{CZ}, \mathrm{HZ}$, and $\mathrm{WZ}$ wrote the paper. All authors read and approved the final manuscript.

\section{REFERENCES}

Adalbert, R., and Coleman, M. P. (2013). Review: axon pathology in agerelated neurodegenerative disorders. Neuropathol. Appl. Neurobiol. 39, 90-108. doi: 10.1111/j.1365-2990.2012.01308.x

\section{ACKNOWLEDGMENTS}

This work was supported by grants from the National Natural Science Foundation of China (No. 81274118), the Key New Drug Creation and Development Program of China (No. 2012ZX09103-201), the Fundamental Research Funds for the Central Universities (No. 2015KJJCA05). Thanks to Fang Fang for providing language help and writing assistance. 
Banker, G. A., and Cowan, W. M. (1979). Further observations on hippocampal neurons in dispersed cell culture. J. Comp. Neurol. 187, 469-493. doi: 10.1002/cne. 901870302

Billups, B., and Forsythe, I. D. (2002). Presynaptic mitochondrial calcium sequestration influences transmission at mammalian central synapses. J. Neurosci. 22, 5840-5847.

Cai, Q., and Tammineni, P. (2016). Alterations in mitochondrial quality control in Alzheimer's disease. Front. Cell. Neurosci. 10:24. doi: 10.3389/fncel.2016.00024

Calkins, M. J., Manczak, M., Mao, P., Shirendeb, U., and Reddy, P. H. (2011). Impaired mitochondrial biogenesis, defective axonal transport of mitochondria, abnormal mitochondrial dynamics and synaptic degeneration in a mouse model of Alzheimer's disease. Hum. Mol. Genet. 20, 4515-4529. doi: $10.1093 / \mathrm{hmg} / \mathrm{ddr} 381$

Calkins, M. J., and Reddy, P. H. (2011). Amyloid beta impairs mitochondrial anterograde transport and degenerates synapses in Alzheimer's disease neurons. Biochim. Biophys. Acta 1812, 507-513. doi: 10.1016/j.bbadis.2011.01.007

Candela, P., Gosselet, F., Saint-Pol, J., Sevin, E., Boucau, M. C., Boulanger, E., et al. (2010). Apical-to-basolateral transport of amyloid-beta peptides through blood-brain barrier cells is mediated by the receptor for advanced glycation end-products and is restricted by P-glycoprotein. J. Alzheimers Dis. 22, 849-859. doi: 10.3233/JAD-2010-100462

Cardoso, S. M., Santana, I., Swerdlow, R. H., and Oliveira, C. R. (2004). Mitochondria dysfunction of Alzheimer's disease cybrids enhances Abeta toxicity. J. Neurochem. 89, 1417-1426. doi: 10.1111/j.1471-4159.2004.02438.x

Chang, D. T., Honick, A. S., and Reynolds, I. J. (2006). Mitochondrial trafficking to synapses in cultured primary cortical neurons. J. Neurosci. 26, 7035-7045. doi: 10.1523/JNEUROSCI.1012-06.2006

Chen, J., Li, S., Sun, W., and Li, J. (2015). Anti-diabetes drug pioglitazone ameliorates synaptic defects in $\mathrm{AD}$ transgenic mice by inhibiting cyclin-dependent kinase5 activity. PLoS ONE 10:e0123864. doi: 10.1371/journal.pone. 0123864

Dahlgren, K. N., Manelli, A. M., Stine, W. B., Baker, L. K., Krafft, G. A., and $\mathrm{LaDu}, \mathrm{M}$. J. (2002). Oligomeric and fibrillar species of amyloid-beta peptides differentially affect neuronal viability. J. Biol. Chem. 277, 32046-32053. doi: 10.1074/jbc.M201750200

Deane, R., Du Yan, S., Submamaryan, R. K., LaRue, B., Jovanovic, S., Hogg, E., et al. (2003). RAGE mediates amyloid-beta peptide transport across the blood-brain barrier and accumulation in brain. Nat. Med. 9, 907-913. doi: 10.1038/nm890

DeKosky, S. T., Scheff, S. W., and Styren, S. D. (1996). Structural correlates of cognition in dementia: quantification and assessment of synapse change. Neurodegeneration 5, 417-421. doi: 10.1006/neur.1996.0056

Dillon, C., and Goda, Y. (2005). The actin cytoskeleton: integrating form and function at the synapse. Annu. Rev. Neurosci. 28, 25-55. doi: 10.1146/annurev.neuro.28.061604.135757

Du, H., Guo, L., Fang, F., Chen, D., Sosunov, A. A., McKhann, G. M., et al. (2008). Cyclophilin D deficiency attenuates mitochondrial and neuronal perturbation and ameliorates learning and memory in Alzheimer's disease. Nat. Med. 14, 1097-1105. doi: 10.1038/nm.1868

Du, H., Guo, L., Wu, X., Sosunov, A. A., McKhann, G. M., Chen, J. X., et al. (2014). Cyclophilin D deficiency rescues Abeta-impaired PKA/CREB signaling and alleviates synaptic degeneration. Biochim. Biophys. Acta 1842(12 Pt A), 2517-2527. doi: 10.1016/j.bbadis.2013.03.004

Du, H., Guo, L., Yan, S., Sosunov, A. A., McKhann, G. M., and Yan, S. S. (2010). Early deficits in synaptic mitochondria in an Alzheimer's disease mouse model. Proc. Natl. Acad. Sci. U.S.A. 107, 18670-18675. doi: 10.1073/pnas.1006586107

Du, H., and Yan, S. S. (2010). Mitochondrial medicine for neurodegenerative diseases. Int. J. Biochem. Cell Biol. 42, 560-572. doi: 10.1016/j.biocel.2010. 01.004

Fang, D., Wang, Y., Zhang, Z., Du, H., Yan, S., Sun, Q., et al. (2015). Increased neuronal PreP activity reduces Abeta accumulation, attenuates neuroinflammation and improves mitochondrial and synaptic function in Alzheimer disease's mouse model. Hum. Mol. Genet. 24, 5198-5210. doi: $10.1093 / \mathrm{hmg} / \mathrm{ddv} 241$

Gao, C., Liu, Y., Jiang, Y., Ding, J., and Li, L. (2014). Geniposide ameliorates learning memory deficits, reduces tau phosphorylation and decreases apoptosis via GSK3 $\beta$ pathway in streptozotocin-induced alzheimer rat model. Brain Pathol. 24, 261-269. doi: 10.1111/bpa.12116
Gylys, K. H., Fein, J. A., Yang, F., Wiley, D. J., Miller, C. A., and Cole, G. M. (2004), Synaptic changes in Alzheimer's disease: increased amyloid-beta and gliosis in surviving terminals is accompanied by decreased PSD-95 fluorescence. Am. J. Pathol. 165, 1809-1817. doi: 10.1016/S0002-9440(10)63436-0

Hansson Petersen, C. A., Alikhani, N., Behbahani, H., Wiehager, B., Pavlov, P. F., Alafuzoff, I., et al. (2008). The amyloid beta-peptide is imported into mitochondria via the TOM import machinery and localized to mitochondrial cristae. Proc. Natl. Acad. Sci. U.S.A. 105, 13145-13150. doi: $10.1073 /$ pnas. 0806192105

Hauptmann, S., Scherping, I., Drose, S., Brandt, U., Schulz, K. L., Jendrach, M., et al. (2009). Mitochondrial dysfunction: an early event in Alzheimer pathology accumulates with age in AD transgenic mice. Neurobiol. Aging 30, 1574-1586. doi: 10.1016/j.neurobiolaging.2007.12.005

Hedskog, L., Pinho, C. M., Filadi, R., Ronnback, A., Hertwig, L., Wiehager, B. et al. (2013). Modulation of the endoplasmic reticulum-mitochondria interface in Alzheimer's disease and related models. Proc. Natl. Acad. Sci. U.S.A. 110 7916-7921. doi: $10.1073 /$ pnas. 1300677110

Hollenbeck, P. J. (2005). Mitochondria and neurotransmission: evacuating the synapse. Neuron 47, 331-333. doi: 10.1016/j.neuron.2005.07.017

Jo, J., Whitcomb, D. J., Olsen, K. M., Kerrigan, T. L., Lo, S. C., Bru-Mercier, G., et al. (2011). $A \beta_{1-42}$ inhibition of LTP is mediated by a signaling pathway involving caspase-3, Akt1 and GSK-3ß. Nat. Neurosci. 14, 545-547. doi: 10.1038/ nn. 2785

Li, Z., Okamoto, K., Hayashi, Y., and Sheng, M. (2004). The importance of dendritic mitochondria in the morphogenesis and plasticity of spines and synapses. Cell 119, 873-887. doi: 10.1016/j.cell.2004.11.003

Liu, W., Li, G., Holscher, C., and Li, L. (2015). Neuroprotective effects of geniposide from Alzheimer's disease pathology. Rev. Neurosci. 26, 371-383. doi: 10.1515/revneuro-2015-0005

Lv, C., Liu, X., Liu, H., Chen, T., and Zhang, W. (2014a). Geniposide attenuates mitochondrial dysfunction and memory deficits in APP/PS1 transgenic mice. Curr. Alzheimer Res. 11, 580-587. doi: 10.2174/1567205011666140618095925

Lv, C., Wang, L., Liu, X., Cong, X., Yan, S. S., Wang, Y., et al. (2014b). Geniposide attenuates oligomeric $\mathrm{A} \beta(1-42)$-induced inflammatory response by targeting RAGE-dependent signaling in BV2 cells. Curr. Alzheimer Res. 11, 430-440. doi: $10.2174 / 1567205011666140514111204$

Lv, C., Wang, L., Liu, X. L., Yan, S. J., Yan, S. S., Wang, Y. Y., et al. (2015). Multifaced neuroprotective effects of geniposide depending on the RAGE-mediated signaling in an Alzheimer mouse model. Neuropharmacology 89, 175-184. doi: 10.1016/j.neuropharm.2014.09.019

Manczak, M., Anekonda, T. S., Henson, E., Park, B. S., Quinn, J., and Reddy, P. H. (2006). Mitochondria are a direct site of A beta accumulation in Alzheimer's disease neurons: implications for free radical generation and oxidative damage in disease progression. Hum. Mol. Genet. 15, 1437-1449. doi: $10.1093 / \mathrm{hmg} / \mathrm{ddl} 066$

Manczak, M., Calkins, M. J., and Reddy, P. H. (2011). Impaired mitochondrial dynamics and abnormal interaction of amyloid beta with mitochondrial protein Drp1 in neurons from patients with Alzheimer's disease: implications for neuronal damage. Hum. Mol. Genet. 20, 2495-2509. doi: 10.1093/hmg/ddr139

Medler, K., and Gleason, E. L. (2002). Mitochondrial $\mathrm{Ca}^{2+}$ buffering regulates synaptic transmission between retinal amacrine cells. J. Neurophysiol. 87, 1426-1439. doi: 10.1152/jn.00627.2001

Penazzi, L., Tackenberg, C., Ghori, A., Golovyashkina, N., Niewidok, B., Selle, K., et al. (2016). Abeta-mediated spine changes in the hippocampus are microtubule-dependent and can be reversed by a subnanomolar concentration of the microtubule-stabilizing agent epothilone D. Neuropharmacology 105, 84-95. doi: 10.1016/j.neuropharm.2016.01.002

Perez-Cruz, C., Nolte, M. W., van Gaalen, M. M., Rustay, N. R., Termont, A., Tanghe, A., et al. (2011). Reduced spine density in specific regions of CA1 pyramidal neurons in two transgenic mouse models of Alzheimer's disease. J. Neurosci. 31, 3926-3934. doi: 10.1523/JNEUROSCI.6142-10.2011

Pozueta, J., Lefort, R., and Shelanski, M. L. (2013). Synaptic changes in Alzheimer's disease and its models. Neuroscience 251, 51-65. doi: 10.1016/j.neuroscience.2012.05.050

Price, K. A., Varghese, M., Sowa, A., Yuk, F., Brautigam, H., Ehrlich, M. E., et al. (2014). Altered synaptic structure in the hippocampus in a mouse model of Alzheimer's disease with soluble amyloid-beta oligomers and no plaque pathology. Mol. Neurodegener. 9:41. doi: 10.1186/1750-1326-9-41 
Reddy, P. H. (2009). Amyloid beta, mitochondrial structural and functional dynamics in Alzheimer's disease. Exp. Neurol. 218, 286-292. doi: 10.1016/j.expneurol.2009.03.042

Reddy, P. H., and Beal, M. F. (2008). Amyloid beta, mitochondrial dysfunction and synaptic damage: implications for cognitive decline in aging and Alzheimer's disease. Trends Mol. Med. 14, 45-53. doi: 10.1016/j.molmed.2007.12.002

Reddy, P. H., Tripathi, R., Troung, Q., Tirumala, K., Reddy, T. P., Anekonda, V., et al. (2012). Abnormal mitochondrial dynamics and synaptic degeneration as early events in Alzheimer's disease: implications to mitochondriatargeted antioxidant therapeutics. Biochim. Biophys. Acta 1822, 639-649. doi: 10.1016/j.bbadis.2011.10.011

Rui, Y., Tiwari, P., Xie, Z., and Zheng, J. Q. (2006). Acute impairment of mitochondrial trafficking by beta-amyloid peptides in hippocampal neurons. J. Neurosci. 26, 10480-10487. doi: 10.1523/JNEUROSCI.3231-06.2006

Sheng, Z. H., and Cai, Q. (2012). Mitochondrial transport in neurons: impact on synaptic homeostasis and neurodegeneration. Nat. Rev. Neurosci. 13, 77-93. doi: $10.1038 / \mathrm{nrn} 3156$

Skulachev, V. P. (2001). Mitochondrial filaments and clusters as intracellular power-transmitting cables. Trends Biochem. Sci. 26, 23-29. doi: 10.1016/S0968-0004(00)01735-7

Stokin, G. B., Lillo, C., Falzone, T. L., Brusch, R. G., Rockenstein, E., Mount, S. L., et al. (2005). Axonopathy and transport deficits early in the pathogenesis of Alzheimer's disease. Science 307, 1282-1288. doi: 10.1126/science.1105681

Takuma, K., Fang, F., Zhang, W. S., Yan, S. Q., Fukuzaki, E., Du, H., et al. (2009). RAGE-mediated signaling contributes to intraneuronal transport of amyloidbeta and neuronal dysfunction. Proc. Natl. Acad. Sci. U.S.A. 106, 20021-20026. doi: 10.1073/pnas.0905686106

Umeda, T., Ramser, E. M., Yamashita, M., Nakajima, K., Mori, H., Silverman, M. A., et al. (2015). Intracellular amyloid beta oligomers impair organelle transport and induce dendritic spine loss in primary neurons. Acta Neuropathol. Commun. 3, 51. doi: 10.1186/s40478-015-0230-2

Verstreken, P., Ly, C. V., Venken, K. J., Koh, T. W., Zhou, Y., and Bellen, H. J. (2005). Synaptic mitochondria are critical for mobilization of reserve pool vesicles at Drosophila neuromuscular junctions. Neuron 47, 365-378. doi: 10.1016/j.neuron.2005.06.018
Yang, J., Seo, J., Nair, R., Han, S., Jang, S., Kim, K., et al. (2011). DGKiota regulates presynaptic release during mGluR-dependent LTD. EMBO J. 30, 165-180. doi: 10.1038/emboj.2010.286

Yin, F., Liu, J., Ji, X., Wang, Y., Zidichouski, J., and Zhang, J. (2011). Silibinin: a novel inhibitor of Abeta aggregation. Neurochem. Int. 58, 399-403. doi: 10.1016/j.neuint.2010.12.017

Zeng, Y., Zhang, J., Zhu, Y., Zhang, J., Shen, H., Lu, J., et al. (2015). Tripchlorolide improves cognitive deficits by reducing amyloid beta and upregulating synapserelated proteins in a transgenic model of Alzheimer's Disease. J. Neurochem. 133, 38-52. doi: 10.1111/jnc.13056

Zhang, Y., Yin, F., Liu, J., Liu, Z., Guo, L., Xia, Z., et al. (2015). Geniposide attenuates insulin-deficiency-induced acceleration of beta-amyloidosis in an APP/PS1 transgenic model of Alzheimer's disease. Neurochem. Int. 89, 7-16. doi: 10.1016/j.neuint.2015.04.002

Zhao, C., Lv, C., Li, H., Du, S., Liu, X., Li, Z., et al. (2016a). Geniposide protects primary cortical neurons against oligomeric $A \beta_{1-42}$-induced neurotoxicity through a mitochondrial pathway. PLoS ONE 11:e0152551. doi: 10.1371/journal.pone.0152551

Zhao, C., Zhang, H., Li, H., Lv, C., Liu, X., Li, Z., et al. (2016b). Geniposide ameliorates cognitive deficits by attenuating the cholinergic defect and amyloidosis in middle-aged Alzheimer model mice. Neuropharmacology 11, 18-29. doi: 10.1016/j.neuropharm. 2016

Conflict of Interest Statement: The authors declare that the research was conducted in the absence of any commercial or financial relationships that could be construed as a potential conflict of interest.

Copyright (c) 2017 Zhang, Zhao, Lv, Liu, Du, Li, Wang and Zhang. This is an openaccess article distributed under the terms of the Creative Commons Attribution License (CC BY). The use, distribution or reproduction in other forums is permitted, provided the original author(s) or licensor are credited and that the original publication in this journal is cited, in accordance with accepted academic practice. No use, distribution or reproduction is permitted which does not comply with these terms. 